\title{
- A poética sincrônica de Haroldo de Campos
}

\section{Cllene Trindade Rohr}

Mestre em Literatura e Crítica Literária pela

PUC-SP.

Resumo: $\mathrm{O}$ objetivo deste trabalho é apresentar a relação dialética entre sincronia e diacronia, sob a perspectiva do poeta e crítico literário Haroldo de Campos, cujo estudo propõe uma análise crítico-estético atual capaz de recuperar e reavaliar os elementos diacrônicos. É imprescindível que o crítico literário opte por um método de pesquisa sincrônica no momento de enfrentamento do texto literário, pois essa escolha permitirá renovar a linha diacrônica por meio de sucessivos cortes sincrônicos que atualizarão a herança literária.

Palavras-chave:Poética sincrônica; Poética diacrônica; Crítica Literária; Haroldo de Campos
Abstract: The objective of this work is to present the dialectical relation between synchrony and diachrony, from the perspective of the poet and literary critic, Haroldo de Campos, whose study proposes a current critical and aesthetic analysis able to recover and reevaluate the diachronic elements. It is essential that the literary critic chooses a synchronous research method, when facing the literary text, because this choice will renew the diachronic line by means of successive synchronous cuts that will bring up to date the literary inheritance.

Keywords: Synchronous poetic; Diachronic poetic; Literary Critic; Haroldo de Campos 

O poeta e crítico literário Haroldo de Campos apresenta-nos em seu livro $A$ arte no horizonte do provável (1969) duas maneiras de abordar o fenômeno literário: o critério histórico - chamado também de diacrônico - e o critério estético-criativo, que pode ser denominado sincrônico. Ao crítico diacrônico interessa o critério histórico ou estudo diacrônico, que consiste na acumulação dos fatos e seus desdobramentos no eixo do tempo, isto é, um estudo meramente documentário em detrimento de um trabalho que valorize esteticamente a obra. Em contrapartida, o crítico sincrônico, que utiliza o método ou critério estético-criativo, coloca em evidência a obra, ressaltando seus aspectos inovadores dentro do seu contexto vigente e também fora dele.

Essa observação situa a discussão sobre o papel do crítico diacrônico e nos leva a repensar nossa própria atuação de críticos na contemporaneidade. Segundo Campos, o crítico diacrônico aceita, sem questionar, a ordem dos fatos que se estabelecem no eixo de sucessão e, além disso, desdenha dos que ousam renovar a tradição literária.

[...] o crítico diacrônico aceita a "média" evolutiva da tradição, o gráfico já historicizado que esta lhe subministra quantoà posição relativa dos escritores nos vários períodos. E olha com olhar cético (o "olho de Medusa" dos guardiões de cemitério, de que fala Sartre...) as revisões e outras tentativas de eversão da ordem constituída, à frente das quais se põem, geralmente, não críticos, mas criadores. (CAMPOS, 1969, p. 206).

O autor critica, rigorosamente, a falta de originalidade dos críticos diacrônicos que, por comodismo, preferem se apoiar no que já está pronto, em vez de inovar a tradição, por meio de um estudo crítico, e, assim, dinamizar a criação a partir de uma nova perspectiva.

Sem desprezar "a tarefa da poética diacrônica como trabalho de levantamento e demarcação do terreno", Campos (1969, p. 207) aponta-lhe as falhas 
para, em seguida, apresentar a poética sincrônica, "muitíssimo menos praticada, mas cuja função tem um caráter eminentemente crítico e retificador sobre as coisas julgadas da poética histórica" (ibidem). Para o autor, a poética sincrônica está inserida na história, e o crítico, apoiado por um estudo estético-criativo, ressaltará o valor da obra literária, observando não só o momento de sua produção, bem como o seu presente atual, pois, assim, estará renovando e atualizando a obra de arte. Mas essa inovação só se estabelece à medida que nos posicionamos criticamente em relação aos padrões impostos pela tradição.

Campos afirma que, para renovar essa tradição, é necessário revisar em profundidade nosso passado poético por meio de uma perspectiva sincrônica e, para esse fim, é importante criar uma Antologia da poesia brasileira de invenção. Essa antologia contribuiria para a renovação de formas em nossa poesia, ampliando e diversificando nosso repertório de informação estética. Desse modo, ressalta Campos que o par sincronia-diacronia deve estar em relação dialética em pelo menos dois níveis:

a) a operação sincrônica se realiza contra um pano de fundo diacrônico, isto é, incide sobre os dados levantados pela visada história, dandolhes relevo crítico-estético atual; b) a partir de cortes sincrônicos sucessivos é possível fazerse um traçado diacrônico renovado da herança literária. (CAMPOS, 1969, p. 215).

O autor observa, ainda, que é necessário reconhecer o valor da obra sem classificar alguns poetas em desprezo de outros, pois o que interessa para o crítico é apontar o valor que cada obra apresenta dentro do seu momento de criação, atualizado pelo presente.

Um exemplo dessa atualização seria uma análise apurada da obra do poeta barroco Gregório de Matos, que é, quase sempre, relegado pelos críticos diacrônicos e colocado, por eles, dentro do eixo linear da história sem 
ressaltar o valor estético de seus textos. De acordo com Campos, Gregório se apropria de elementos do barroco e os incorpora à textura de sua linguagem, criando a "miscigenação idiomática de caldeamento tropical" (CAMPOS, 1969, p. 2009), que traduz o hibridismo do nosso barroco. A obra de Gregório ganharia destaque se fosse estudada com a merecida atenção de uma crítica estético-evolutiva que leve em consideração a "questão da dignidade estética da tradução como categoria da criação ${ }^{1 "}$ (CAMPOS, 1969, p. 209).

O conceito de poética sincrônica, formulado por Campos, se apoia na teoria de Roman Jakobson e foi, também, adotado recentemente por Gérard Genette a propósito da "História Estrutural da Literatura", que nada mais é que a atualização e a renovação de perspectivas diacrônicas, a partir de cortes sincrônicos. Desse modo, Campos elabora seu método de estudo, afirmando que

a poética sincrônica procura agir crítica e retificadoramente sobre as coisas julgadas da poética diacrônica. Sincronia e diacronia estão, pois, como é obvio, em relação dialética. [...] A escolha de uma perspectiva sincrônica é, antes de mais nada, uma disposição metodológica, a maneira de privilegiar, para efeitos práticos, um ponto de vista estrutural. (CAMPOS, 1969, p. 214).

A escolha por uma poética sincrônica implica, como vemos, um método que visa a um ponto de vista estrutural, isto é, um estudo que observa e analisa a obra em sua forma, atribuindo-lhe um valor estético criativo capaz de responder a possíveis questionamentos. Como exemplifica Campos, o intento é ter "uma visão não diversa do poema como máquina lúdica e estrutura combinatória [que] informa alguns dos 'poemas partidos em dois' de A educação pela pedra, de João Cabral de Melo Neto." (CAMPOS, 1969, p. 210).
${ }^{1}$ É importante salientar que Campos desenvolveu um estudo aprofundado sobre a tradução como criação que se encontra em seu livro Metalinguagem e outras metas, no capítulo intitulado " $\mathrm{Da}$ tradução como criação e como crítica". 
Outro exemplo é o de Odorico Mendes, cuja classificação taxativa de Silvio Romero considerou suas traduções como "monstruosidades". Entretanto, se colocarmos sua obra diante da análise sincrônica, constataremos que seu trabalho não pode ser minimizado, tendo em vista a maleabilidade de construções vocabulares que exploram paradigmas com significado em sua tradução homérica. A formação da palavra táctil em Odorico abriu o caminho para as criações linguísticas de Sousândrade e Guimarães Rosa no nosso tempo.

Campos insiste na metodologia sincrônica porque clama, em seus textos, por uma renovação da poética brasileira a partir de um estudo que possibilite uma leitura da época de criação da obra de arte, à luz de concepções estético-atuais. Assim sendo, obter-se-á uma relação dialética de integração e complementaridade entre sincronia e diacronia que fará emergir o valor estético do texto literário. Sem dúvida, esse é o maior desafio da crítica atual que adota o método da poética sincrônica.

Nesse sentido, o valor do crítico literário é reconhecido não por seus argumentos expostos e sim pela sua escolha metodológica no momento de avaliar a obra, pois ele deve ter sempre em mente não só a época de criação da obra, bem como as concepções estéticas atuais. Essa escolha deve, portanto, contemplar uma "postura histórico-evolutiva [que] inclui sempre, necessariamente, um quadro sincrônico assumido como tábua de valor" (CAMPOS, 1969, p. 222).

Ao assinalar, nos termos de Saussure, a dicotomia entre diacronia e sincronia, Campos distingue o conceito de poética sincrônica - pensado pelos críticos de mentalidade diacrônica - da sua proposta inovadora de poética sincrônica estético-evolutiva. Para ele, o quadro sincrônico adotado pelos críticos diacrônicos é, também, um quadro historicizado, ou seja, está subordinado à tradição.

Já a poética sincrônica, definida nos termos do poeta concretista, "está imperativamente vinculada às 
necessidades criativas do presente" (CAMPOS, 1969, p. 222). Ao invés de ser determinada pela descrição sincrônica, a poética estético-evolutiva ou sincrônica de Campos quer substituí-la com a finalidade de revisar o critério diacrônico.

Embora não despreze o trabalho da crítica diacrônica, Campos a critica com afinco porque, muitas vezes, ela revela uma atitude de anuência passiva ao classificar alguns poetas como "menores". O crítico de visada sincrônica, por sua vez, romperá com a visão historicizada e dará o destaque que a obra merece, se sua sensibilidade e informação estiverem aferidas pelas exigências estético-criativas do tempo presente.

O que o poeta nos oferece com o estudo da relação dialética entre diacronia e sincronia é um método diferente quanto à maneira de abordar o texto literário. Esse método oferece subsídios para a renovação de uma poética pautada na análise superficial e linear do texto literário. É preciso elevar a obra de arte e outorgar-lhe o devido valor, resgatando escritores, poetas e obras da obscuridade a que foram submetidos por tanto tempo.

Todavia, a proposta de Campos não tem recebido a atenção merecida por parte da crítica, sobretudo a atual, e tem sido muito pouco adotada por ela. Esse fato ocorre não somente por comodismo, mas, especialmente, porque os textos de Campos possuem uma linguagem marcada pelo caráter desafiador e confrontador que desperta no leitor - que se intitula crítico - a rejeição diante de uma abordagem que é diferente e inovadora. Talvez, essa rejeição só ocorra porque esse leitor ainda não foi incitado para despertar sua consciência crítica e privilegiar o novo; e, consequentemente, assim como certos críticos, continua valorizando o lugar-comum. 


\section{Referência}

CAMPOS, Haroldo de. Poética sincrônica; O samurai e o kakemono; Diacronia e sincronia In: $A$ arte no horizonte do provável. São Paulo: Perspectiva, 1969. 